\title{
Determination of plant silicon content with near infrared reflectance spectroscopy
}

\section{Adriaan Smis ${ }^{1,2 * t}$, Francisco Javier Ancin Murguzur ${ }^{2+}$, Eric Struyf ${ }^{1}$, Eeva M. Soininen ${ }^{2}$, Juan G. Herranz Jusdado ${ }^{2}$, Patrick Meire ${ }^{1}$ and Kari Anne Bråthen ${ }^{2}$}

Ecosystem Management Research Group, University of Antwerp, Antwerp, Belgium

${ }^{2}$ Department of Arctic and Marine Biology, UiT - The Arctic University of Norway, Tromsø, Norway

\section{Edited by:}

Jane DeGabriel, University of

Western Sydney, Australia

Reviewed by:

Ben David Moore, University of

Western Sydney, Australia

William Foley, Australian National

University, Australia

*Correspondence:

Adriaan Smis, Ecosystem

Management Research Group,

University of Antwerp,

Universiteitsplein 1,

2610 Antwerp, Belgium

e-mail: adriaan.smis@

uantwerpen.be

${ }^{\dagger}$ Shared first authorship.
Silicon (Si) is one of the most common elements in the earth bedrock, and its continental cycle is strongly biologically controlled. Yet, research on the biogeochemical cycle of Si in ecosystems is hampered by the time and cost associated with the currently used chemical analysis methods. Here, we assessed the suitability of Near Infrared Reflectance Spectroscopy (NIRS) for measuring Si content in plant tissues. NIR spectra depend on the characteristics of the present bonds between $\mathrm{H}$ and $\mathrm{N}, \mathrm{C}$ and $\mathrm{O}$, which can be calibrated against concentrations of various compounds. Because $\mathrm{Si}$ in plants always occurs as hydrated condensates of orthosilicic acid $\left(\mathrm{Si}(\mathrm{OH})_{4}\right)$, linked to organic biomolecules, we hypothesized that NIRS is suitable for measuring $\mathrm{Si}$ content in plants across a range of plant species. We based our testing on 442 samples of 29 plant species belonging to a range of growth forms. We calibrated the NIRS method against a well-established plant Si analysis method by using partial least-squares regression. Si concentrations ranged from detection limit $(0.24 \mathrm{ppmSi})$ to $7.8 \% \mathrm{Si}$ on dry weight and were well predicted by NIRS. The model fit with validation data was good across all plant species ( $n=141$, $R^{2}=0.90$, RMSEP $=0.24$ ), but improved when only graminoids were modeled $(n=66$, $R^{2}=0.95$, RMSEP $=0.10$ ). A species specific model for the grass Deschampsia cespitosa showed even slightly better results than the model for all graminoids $\left(n=16, R^{2}=0.93\right.$, RMSEP $=0.015$ ). We show for the first time that NIRS is applicable for determining plant Si concentration across a range of plant species and growth forms, and represents a time- and cost-effective alternative to the chemical Si analysis methods. As NIRS can be applied concurrently to a range of plant organic constituents, it opens up unprecedented research possibilities for studying interrelations between $\mathrm{Si}$ and other plant compounds in vegetation, and for addressing the role of $\mathrm{Si}$ in ecosystems across a range of $\mathrm{Si}$ research domains.

Keywords: NIRS, plant silica concentration, calibration, Fennoscandia, ecosystem research, graminoids, Deschampsia cespitosa

\section{INTRODUCTION}

Silicon $(\mathrm{Si})$ is widely present in the plant kingdom. In most plant species, plant $\mathrm{Si}$ constitutes $\sim 0.1$ up to $2 \%$ of Si by plant dry weights (Epstein, 1994; Hodson et al., 2005). Remarkably high average concentrations in some plant groups such as horsetails ( $\sim 3 \%$ Si by dry weight), and grasses $(\sim 1.5 \%$ Si by dry weight; Hodson et al., 2005) suggest that Si can have an essential role in plants. Si supports plant growth, improves the plant structural strength, viability, reproduction and resistance against biotic (e.g., parasitism, pests, herbivory) and abiotic (e.g., metal toxicity, salinity, drought) stresses, as well as increases the efficiency of light interception (Epstein, 1999; Ma et al., 2001). Hence there are compelling reasons to study $\mathrm{Si}$ in plants. However, the importance of plant $\mathrm{Si}$ reaches beyond the plant kingdom as the Si-assimilation of plants is coupled to the global biogeochemical $\mathrm{Si}$ and C cycling (Street-Perrott and Barker, 2008). Plants significantly increase mineral silicate weathering and the coupled
$\mathrm{CO}_{2}$ drawdown (Kelly et al., 1998; Moulton et al., 2000). Plant Si uptake functions as a "terrestrial Si filter" (Struyf and Conley, 2012), controlling the continuous delivery of Si to rivers that connect the continental Si cycle to the coastal and oceanic Si cycle (Tréguer and De La Rocha, 2013). As such, plant biosilicification is tightly linked to aquatic eutrophication problems (Cloern, 2001), and the strength of the oceanic carbon sequestration (Ragueneau et al., 2006), making the study of plant Si in terrestrial ecosystems instrumental to climate change studies.

Despite the increasing interest, the quantification of biogenic silica (bSi) in terrestrial ecosystems is hampered by the timeintensive and relatively expensive chemical analysis methods for bSi. In most studies, the total plant Si content, further indicated as plant bSi, is analyzed by chemical digestion followed by a colorimetric or a spectrophotometric analysis method (e.g., Massey et al., 2007; Saccone et al., 2007; Vandevenne et al., 2012; Carey and Fulweiler, 2013; Meunier et al., 2013), or by wet or 
dry ashing followed by gravimetric analysis (e.g., Carnelli et al., 2001; Ma et al., 2001; Blecker et al., 2006). These methods are destructive, time-intensive and require chemical pre-treatment. Especially in large-scale studies and monitoring programs, more efficient methods are warranted for a better understanding of both the role of $\mathrm{Si}$ in ecosystems as well as the biosilicification at the scale of entire ecosystems.

In this study, we address the applicability of a comparable non-destructive method, Near Infrared Reflectance Spectroscopy (NIRS), for the analysis of Si in plants. NIRS has been used intensively in agricultural and industrial research (e.g., Shenk and Westerhaus, 1994), and is receiving increasing interest in ecology after numerous successful ecological applications have been demonstrated, mostly for the determination of plant primary and secondary organic compounds and parameters related to the food quality of plants (e.g., Stolter et al., 2006; Chodak, 2008). Plant material absorbs near infrared radiation (NIR) where there is presence of chemical bonds between hydrogen $(\mathrm{H})$ and other atoms (e.g., C-H, N-H, O-H; Kaye, 1954). Si occurs in plants in and between plant cells as amorphous opal silica structures called phytoliths or phytogenic Si (Sangster and Hodson, 1986; Piperno, 1988). These structures are always composed of hydrated condensates of orthosilicic acid $\left(\mathrm{Si}(\mathrm{OH})_{4}\right)$, containing mostly Si$\mathrm{O}-\mathrm{Si}$ bonds, and some hydroxyl groups $\left(\mathrm{SiO}_{2} \cdot \mathrm{nH}_{2} \mathrm{O}\right.$; Currie and Perry, 2007). In addition, these silica structures show strong interactions with several plant biomolecules (e.g., cellulose; Perry and $\mathrm{Lu}, 1992)$. Although Si never directly binds to $\mathrm{H}$, the hydrated silica structures probably interact with their plant organic environment through hydroxyl groups (Zhang et al., 2013) and are expected to result in a specific NIR absorption signature of plant bSi. This suggests a possibility to apply NIRS as analysis method of plant $\mathrm{Si}$.

The reasons to apply NIRS are manifold: samples need minor pre-treatment without the use of chemicals, the analysis itself is rapid, non-destructive, allows repeated measurements, and it provides information about many plant parameters from a single sample (Foley et al., 1998). Recently, X-ray fluorescence (XRF) spectroscopy was presented as a more rapid and accurate alternative to digestion-based chemical techniques (Reidinger et al., 2012). Although XRF spectroscopy has shown to have the same advantages regarding analysis time, analysis cost, and sample consumption, XRF spectroscopy cannot be used for the simultaneous analysis of numerous plant organic compounds for which NIRS have been shown to be successful and which are often of great interest in ecological research (e.g., Schaller et al., 2012).

The applicability of NIRS for Si analysis has been tested using agricultural (alfalfa hay, rice straw) and bio-industrial products (sugar mill mud and ash; Halgerson et al., 2004; Jin and Chen, 2007; Ostatek-Boczynski et al., 2013). Although they all suggested a potential applicability of NIRS, none of these studies showed sufficiently strong calibrations for direct application on plant material. Jin and Chen (2007) used the insoluble ash method for their reference values, although this method was only recommended if the content of indigestible mineral residues is sought (Van Soest and Jones, 1968). Halgerson et al. (2004) used a calibration data set with a very narrow concentration range around and average Si concentration of $0.02 \%$, and Ostatek-Boczynski et al. (2013) only tested NIRS on industrially processed plant material (sugar mill by-products). For ecological applications, the widespread nature of Si in the plant kingdom calls for testing the general applicability of NIRS, i.e., a method that can be applied both to the wide range of plant taxa and over the typical concentration range in which bSi is found in nature. With support from these moderately successful pioneer studies, we hypothesize in this study that NIRS may be applied for measuring the Si content of plants.

\section{MATERIALS AND METHODS PLANT SAMPLING}

The study was performed in the alpine parts of the northern, subarctic zone of Norway (Finnmark). Plant species were sampled from eight river valleys, extending the temperature gradient of the region. The sampled plant species (Table 1 ) are typical for the riparian zone, dominated by willows, forbs and grasses, and for the surrounding dry heath tundra, dominated by dwarf shrubs. Each sample consisted of several plant individuals from the same location, and habitat, with a maximum distance of $25 \mathrm{~m}$ from each other. Plant individuals were always sampled by harvesting the green non-woody plant parts; the whole plant in the case of grasses, forbs and horsetails, and the leaves in the case of shrubs (Table 1). Plant material was cut some centimeters above the soil level and sampled plant material was always visually controlled to be free from soil particles. Samples of 29 plant species, representing different growth forms, were collected making a total of 442 plant samples (Table 1). In order to cover plant and Si structural variations over several plant development stages, we sampled plant species at the beginning (June), during (July) and at the end of the growing season (August).

\section{THE REFERENCE CHEMICAL ANALYSIS METHOD}

Plant samples were oven dried for 3 days at $75^{\circ} \mathrm{C}$. We chose not to wash the plant samples as sampling routines excluded the presence of soil particles and the ecological context (high precipitation, dense vegetation, long distance to roads) restricted the possibilities for aeolean dust/soil transport. Subsequently, samples were pulverized using a ball mill (Mixer Mill, MM301; Retsch GmbH and Co. Haan, Germany) in order to get very fine and homogeneous plant material. We applied a chemical digestion followed by a colorimetric analysis, as the gravimetric approach has been proven to show a poor reproducibility (Herbauts et al., 1994). Plant bSi was extracted by the wet alkaline $\left(0.1 \mathrm{M} \mathrm{Na}_{2} \mathrm{CO}_{3}\right)$ extraction, a technique recently confirmed to be suitable for bSi analysis of plant material (Meunier et al., 2013). About $30 \mathrm{mg}$ of pulverized plant material was incubated for $4 \mathrm{~h}$ in $0.1 \mathrm{M} \mathrm{Na}_{2} \mathrm{CO}_{3}$ at $80^{\circ} \mathrm{C}$ (DeMaster, 1991) and then $10 \mathrm{ml}$ of the extract was filtered (Chromafil ${ }^{\circledR} \mathrm{A}-45 / 25$, pore size of $0.45 \mu \mathrm{m}$ ). After extraction, samples were stored in a dark room at $3^{\circ} \mathrm{C}$ and were analyzed colorimetrically for extracted dissolved Si (DSi) within a maximum of 2 weeks, using a Continuous Flow Analyser (CFA; SKALAR SA 1500, Smith and Milne, 1981). Blank extractions were subtracted to account for Si release from recipients and chemicals. The error of the entire analysis procedure was measured as the (reproducibility) standard deviation of the analysis of 
Table 1 | Overview of plant species, plant part, sample size $(n)$, and the plant silicon concentration range, average value and the coefficient of variation of the plant silicon concentration for all studied growth forms with species alphabetically ordered within each growth form.

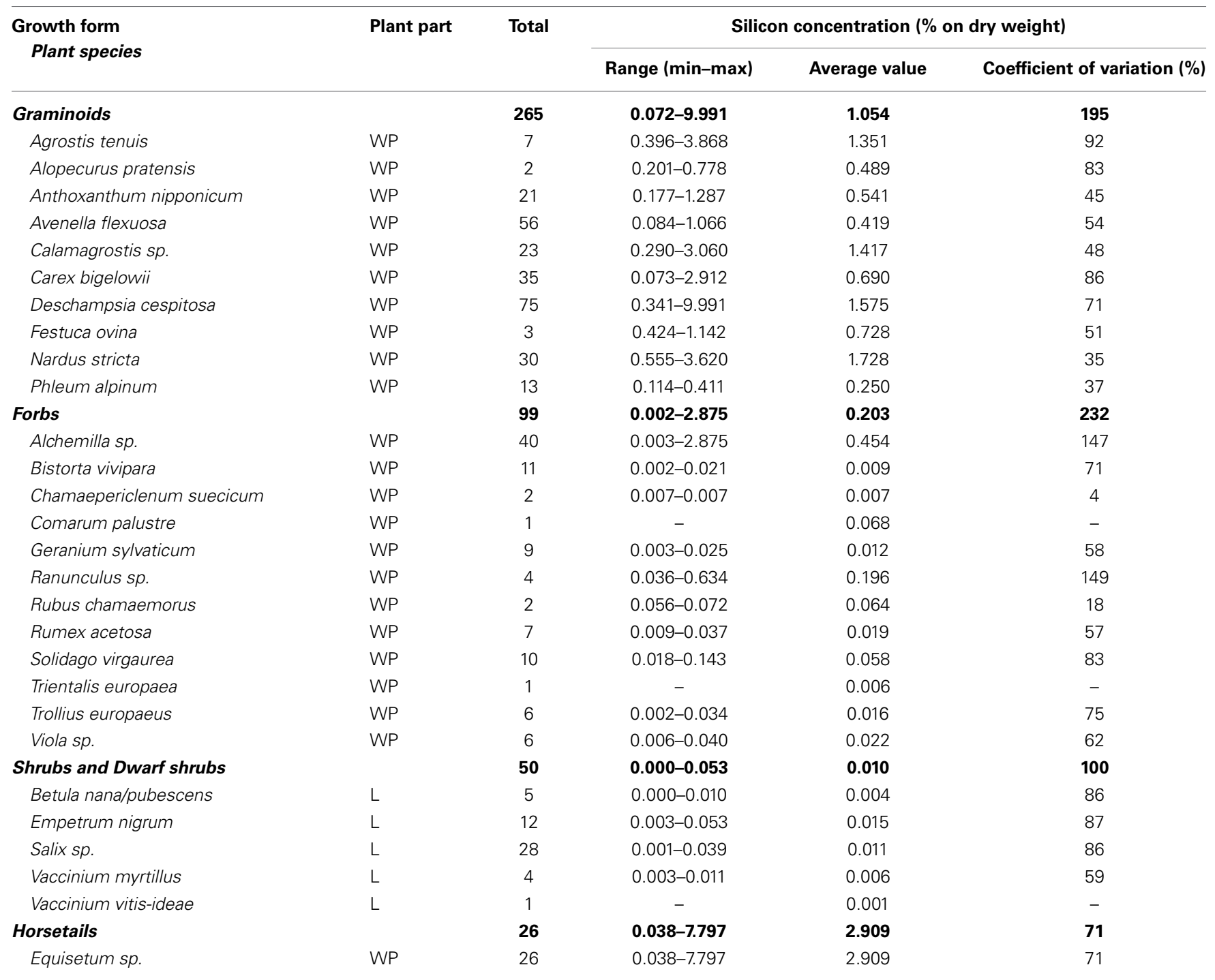

WP, whole plant; L, leaves.

12 subsamples of a single pulverized plant sample (Deschampsia cespitosa).

\section{ANALYSIS WITH NIRS}

Remaining pulverized plant samples were made into tablets ( $16 \mathrm{~mm},>1 \mathrm{~mm}$ thick) by applying 6 tons of pressure with a hydraulic press, in order to obtain a homogeneous flat surface. A homogeneous flat surface reduces random light scatter of loose powder, thus reducing random variation in spectral signatures. Before NIRS analyses, the plant tablets were oven dried at $50^{\circ} \mathrm{C}$ for $2 \mathrm{~h}$ in order to remove the remaining water film on the hydrophilic plant material. The dry samples were then cooled in a desiccator until scanning by NIRS. The NIRS-spectra, measured as the logarithm of the inversed reflectance $(\log (1 / \mathrm{R}))$, were recorded with monochromatic radiation at $1.4 \mathrm{~nm}$ intervals from 350 to $1050 \mathrm{~nm}$, and at $2 \mathrm{~nm}$ intervals from 1000 to $2500 \mathrm{~nm}$, using a FieldSpec 3 (ASD Inc., Boulder, Colorado, USA) and were registered at $1 \mathrm{~nm}$ interpolated intervals. Each sample spectrum was recorded as the average of three replicate scans. NIRS scanning was performed at room temperature during one single winter day, which most likely resulted in a stable room temperature as there was no sunlight to warm up the room.

\section{CALIBRATION AND VALIDATION}

Three nested calibration sets were created; one on the total sample size, representing all studied plant species $(n=442)$; one for a subset containing all graminoids $(n=264)$, which are, as active $\mathrm{Si}$ accumulators, most often studied in plant-Si studies, and finally, in order to test the performance of NIRS when applied to one single plant species, one calibration for a subset containing all samples of the grass species Deschampsia cespitosa $(n=75)$. All data sets were treated similarly: in order to get a similar spectral diversity within the calibration and validation dataset, calibration and validation samples were selected using the Kennard-Stone 
algorithm (Kennard and Stone, 1969) included in the "prospectr" package 0.1.3 (Stevens and Ramirez-Lopez, 2014) in R 3.0.1 (R Development Core Team, 2013). Spectral outliers were identified by means of Mahalanobis distances (75\% quantile as cutoff point; Mahalanobis, 1936; De Maesschalck et al., 2000) and removed in a single operation. Before starting the calibration, the wavelength regions where the NIRS sensors overlapped $(350-380 \mathrm{~nm}$, $760-840 \mathrm{~nm}, 1700-1800 \mathrm{~nm}$ and $2450-2500 \mathrm{~nm}$ ) were removed to avoid false correlations from instrumental noise.

The statistical procedure for the calibration, using partial leastsquares regression (Martens and Næs, 1993), in the pls-package 2.4-3 (Mevik et al., 2013) in R 3.1.0. Different transformations on the spectral data set were considered for the calibrations: scaling and/or centering, smoothing before applying derivatives, and the use of first (1D) and second order derivatives (2D) by using the earlier mentioned "prospectr" package (Stevens and Ramirez-Lopez, 2014) in R.

The most parsimonious calibration model was chosen based on evaluation of two calibration statistics: a high coefficient of multiple determination $\left(R^{2}\right)$, and the lowest root mean square error of calibration (RMSEC) for a given number of selected model components $k$. Overfitting was avoided by selecting the combination of model parameters $k$ showing the lowest standard error of cross-validation (SECV; Mark and Workman, 1991). Finally, the chosen calibration model was used to predict the Si concentrations of the validation sample sets. The $R^{2}$, the RMSEP ("root mean square error of prediction," i.e., the mean error rate between predicted and real values), the bias (i.e., the systematic error of the linear regression), and the intercept and slope of the linear fit of the predictions were used to assess the applicability of the developed NIRS calibration models. We tested the quality of all calibration models with and without the visible region (380-720 nm). Chlorophyll has a strong signature in the visible light spectra, and seasonal variation in chlorophyll content could consequently be confounded with variation in bSi content. As the models with visible light were consistently of lower quality, we only present models without the visible light.

\section{RESULTS}

\section{PLANT SI CONCENTRATIONS}

We found plant Si concentrations to range from the detection limit $(<0.024 \% \mathrm{Si})$ to $10.0 \%$ of Si by dried plant weight. The average error of the wet chemical analysis method, measured as the reproducibility standard deviation of the repeated measurement of a Deschampsia cespitosa sample with average concentration of $0.34 \% \mathrm{Si}$, was $0.022 \%$ of Si by dry weight, which corresponds to an average relative error of $2.6 \%$. Across all species, plant Si concentration showed large variation with a coefficient of variation of $69 \%$. However, the concentrations of Si were low $(<0.1 \% \mathrm{Si})$ for almost all shrubs, dwarf shrubs and forbs, while most graminoids and horsetails showed average Si concentrations higher than $0.5 \%$ (Table 1). The selection of the calibration and validation datasets based on the spectral characteristics of the samples resulted in comparable Si concentration frequency distributions of the calibration and validation datasets for the three separate models (Figure 1).

\section{THE NIRS CALIBRATION MODELS}

The best calibration model for Si across all plant species was based on the second order derivatives (2D) of the smoothed (17 wavelength intervals) NIR spectra with 23 components, which showed highest loading values at 1050, 1900, and $2300 \mathrm{~nm}$ (Figure 2). The best calibration model for graminoids was based on the multiplicative-scatter corrected spectra, and 33 components. Highest loading values were found for wavelengths around 1900 and $2300 \mathrm{~nm}$ (Figure 3). Finally, the best calibration model for the grass species Deschampsia cespitosa was based on the centered, second order derivative spectra with 19 components, with highest loading values for the same wavelengths as the calibration model including all plant species (Figure 4).

Our calibration model including 442 samples from 29 different plant species showed a RMSEP of $0.24 \%$ of Si by dry weight (Table 2, Figure 5), corresponding to a relative error of $28 \%$ for the average measured Si concentration. Our separate calibration model for graminoids showed a RMSEP of $0.10 \%$ of $\mathrm{Si}$ by dry weight, corresponding to an average relative error of only $8.3 \%$ (Table 2, Figure 6). Narrowing the graminoid dataset to the most abundant grass species, Deschampsia cespitosa, increased the calibration model accuracy; a RMSEP of $0.023 \%$ of Si by dry weight, corresponding to a relative error of $1.3 \%$ (Table 2, Figure 7). The bias was also highest for the model including all plant species, whereas it was lowest and similar for the graminoids and Deschampsia cespitosa (Table 2). For the models including all plant species and the graminoids, the slope and intercept of the validation regression lines were close to 0 and 1 respectively, whereas the Deschampsia cespitosa model showed a slope close to one, and an intercept which differed more from 0 (Table 2). The $R^{2}$ values of the validation regression were all equal to or higher than 0.90 and showed a similar pattern as the bias, with

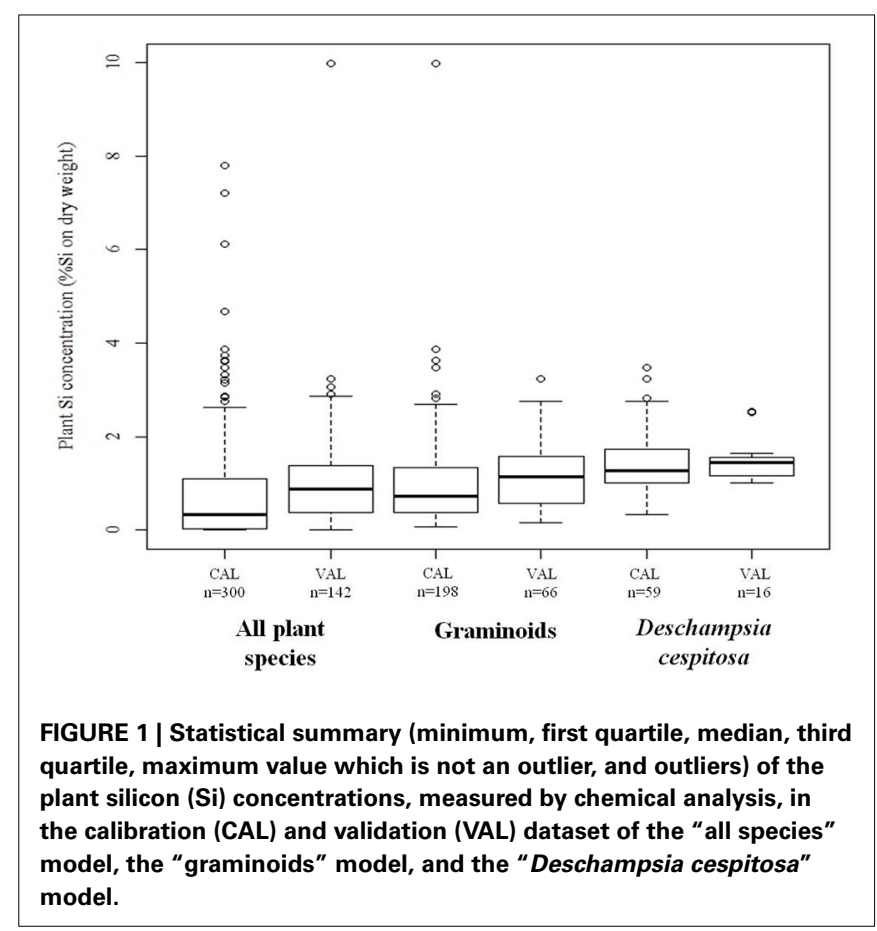




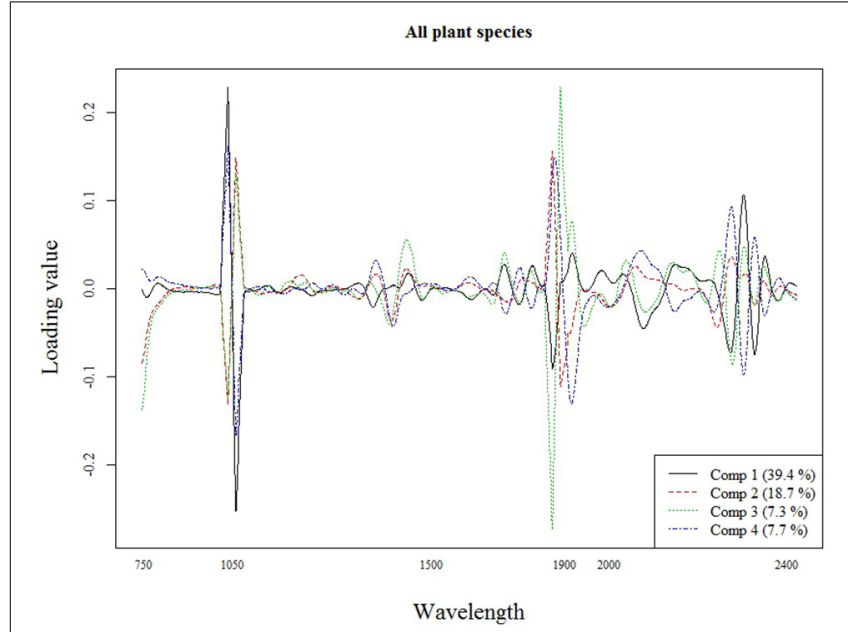

FIGURE 2 | Loading plot for the most important components of the calibration model for all plant species.

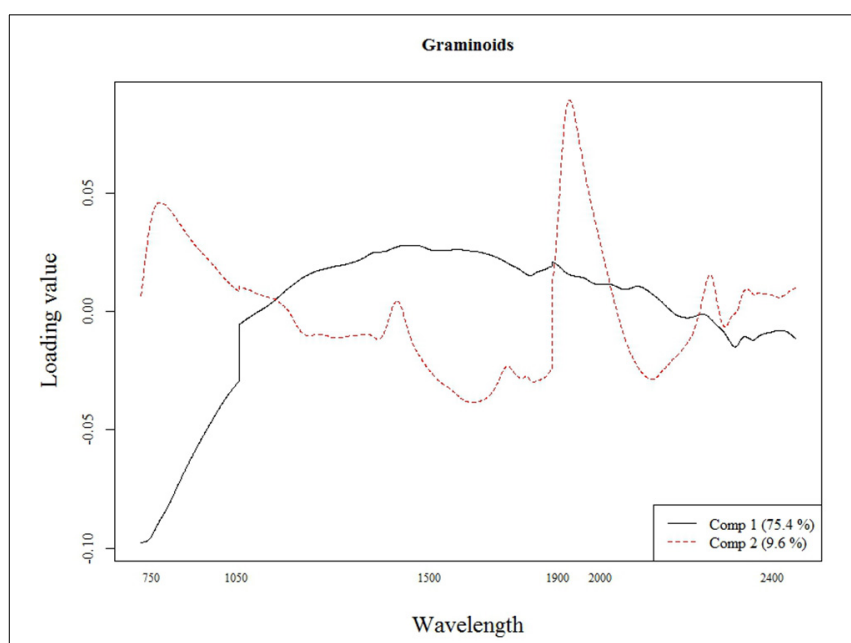

FIGURE 3 | Loading plot for the most important components of the calibration model for the graminoids.

the highest value for the graminoids model (0.95), the lowest for the model including all plant species (0.90) and an intermediate value for the Deschampsia cespitosa model (0.93; Table 2, Figures 5-7).

\section{DISCUSSION \\ THE QUALITY OF THE NIRS CALIBRATION MODEL}

Our results show that the Si content of plants can successfully be measured by NIRS across a large range of plant species. All three calibration models showed a high coefficient of determination $\left(R^{2} \geq 0.9\right)$. The calibration model for the grass Deschampsia cespitosa showed the best overall performance with the lowest root mean square error in the validation (RMSEP), and a slope closest to 1 (Table 2). Taking into account that the average error of the wet chemical extraction method followed by a colorimetric analysis is $0.022 \%$ of Si by dry weight, using NIRS for graminoids

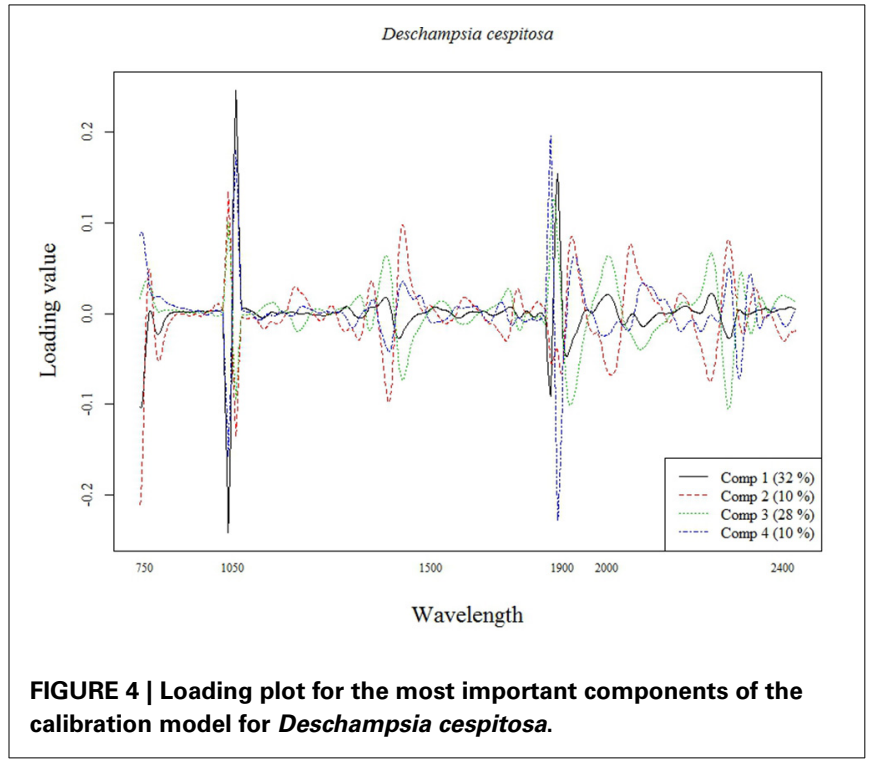

increases the average error with $0.078 \%$ of $\mathrm{Si}$ by dry weight, which is acceptable when working with plants accumulating $\mathrm{Si}$ (Si $>0.5 \%$ Si by dry weight; Raven, 2003). For the Deschampsia cespitosa model, the average error became slightly lower compared to the reference chemical analysis method $(0.015 \% \mathrm{Si}$ vs. $0.022 \% \mathrm{Si}$ ). Also, a further specification of the calibration model from all plant species to the plant group level and finally to a single plant species increased the accuracy. Prudence is called for when using the calibration model across all plant species in studies that require very high accuracy. Although the model containing all plant species showed a high $R^{2}$, and an intercept and slope close to 0 and 1, respectively, it was characterized by a RMSEP of $0.24 \%$ of Si by dry weight, which is rather high, even for plant species actively accumulating Si.

Our three calibration models showed remarkably better validation statistics compared to earlier studies on the application of NIRS of plant material (Halgerson et al., 2004; Jin and Chen, 2007; Ostatek-Boczynski et al., 2013), and is probably a result of (1) the use of a well-proven and widely used reference method for plant Si analysis (Meunier et al., 2013), and (2) a calibration dataset which consists of plant species representing almost the entire range of natural plant $\mathrm{Si}$ concentrations (Hodson et al., 2005). We also hypothesize that the specific pre-treatment of the plant samples before NIRS scanning, where we pressed ground plant powder into a tablet, may have increased the quality of the calibration. The ball-mill produced very fine powder, resulting in a flat tablet surface which may have reduced both light scattering from powder and original structural differences between plant species. However, as we were not able to measure the fineness, particle size distribution and homogeneity of the ground plant samples, this issue remains subject for further research and the quality of the NIRS calibration could potentially be increased by using a cyclotech mill instead of the ball mill procedure. The cyclotech mill grinding method ensures a narrow particle size distribution, which has been proven to strongly influence the NIR spectrum (Casler and Shenk, 1985). 
Table 2 | Calibration and validation statistics $\left(R^{2}\right.$ : coefficient of determination; RMSEC: root mean square error of calibration; RMSEP: root mean square error of prediction) of the Partial Least Squares regression models on NIR spectra for the analysis of plant Si concentration in three separate models.

\begin{tabular}{|c|c|c|c|c|c|c|c|c|c|c|}
\hline Calibration model & \multicolumn{4}{|c|}{ Model selection: calibration } & \multicolumn{6}{|c|}{ Model quality: validation } \\
\hline All plant species & 23 & 300 & 0.88 & 0.3327 & 141 & 0.90 & 0.2379 & -0.054 & -0.0009 & 0.95 \\
\hline Graminoids & 33 & 198 & 0.91 & 0.2076 & 66 & 0.95 & 0.1021 & -0.032 & 0.0070 & 0.97 \\
\hline Deschampsia cespitosa & 19 & 59 & 0.95 & 0.1357 & 16 & 0.93 & 0.0150 & -0.035 & -0.0660 & 1.02 \\
\hline
\end{tabular}

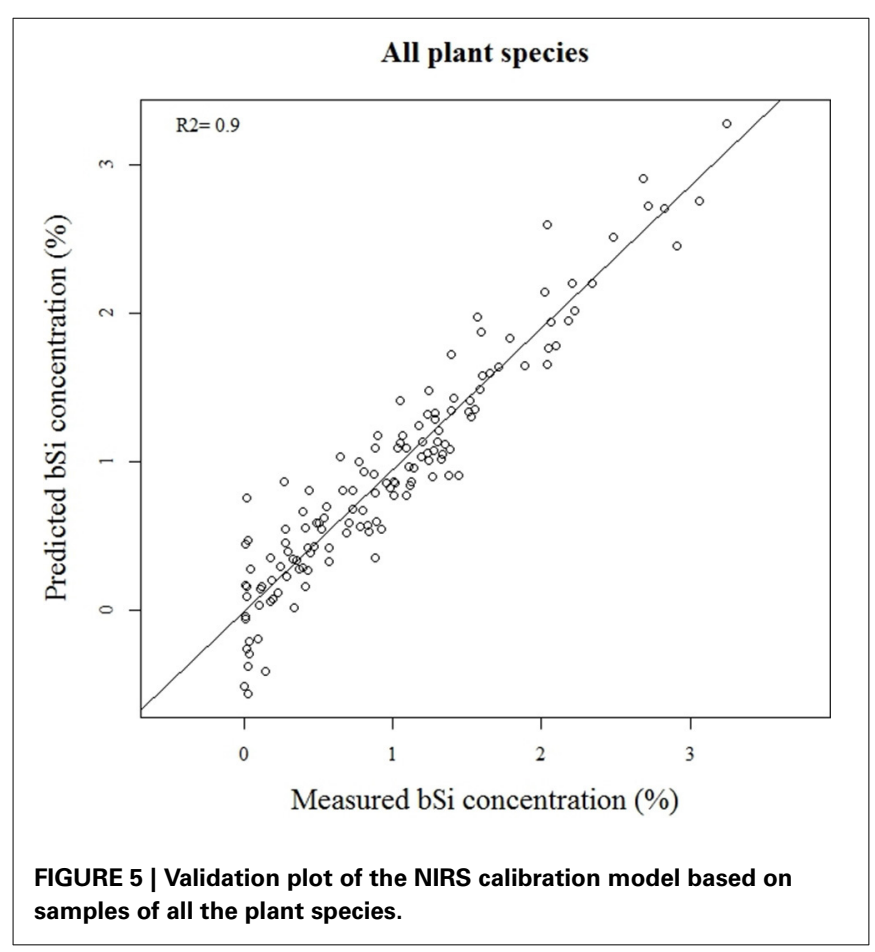

\section{NIRS CALIBRATION AND PLANT SI BIOCHEMISTRY}

Our success in measuring Si with NIRS across several plant lineages, representing different plant phenological stages and a range of ecological contexts, may also be due to the single type of Si structure in plants. Whereas the often transient and speciesspecific character of associations between minerals and organic or hydrated molecules (Clark et al., 1987) may limit the applicability of NIRS for mineral analysis to a well-defined population (plant species, sampling time; Foley et al., 1998), Si in plants is only known to occur as a hydrated condensate of orthosilicic acid $\left(\mathrm{Si}(\mathrm{OH})_{4}\right)$. However, narrowing the calibration dataset to graminoids and finally to Deschampsia cespitosa resulted in a clear increase in accuracy (lower RMSEP) and a regression slope close to one in the case of Deschampsia cespitosa. We suggest that this increase in calibration model accuracy is related to plant group/species dependent locations of bSi formation. Cell-silicification shows clear phylogenetic differences. In monocotyledons, silica is more often deposited in the cell lumen of "silica cells," and as "silica bodies" on cells, while dicotyledons more often show silica deposits within or underneath the cell

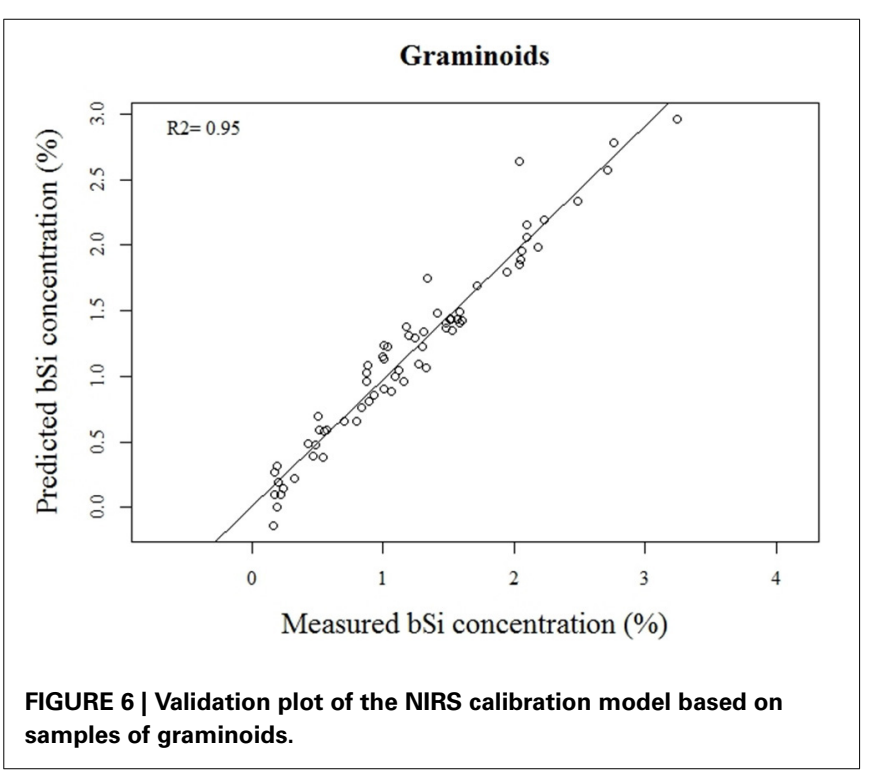

wall (Piperno, 1988). In addition, plant lineages differ in the type of tissues which are silicified; in grasses, $\mathrm{Si}$ is preferentially deposited as a layer beneath the cuticle (Prychid et al., 2004), the Pteridaceae (ferns) and Equisetaceae (horsetails) mostly show silicification within and at epidermal cells (Kaufman et al., 1971; Sundue, 2009), while orchids (Orchidaceae) are characterized by silica bodies in the sclerenchyma (Møller and Rasmussen, 1984). Moreover, depending on the condensation environment (e.g., $\mathrm{Si}(\mathrm{OH})_{4}$ concentration, temperature, $\mathrm{pH}$ ), the silica condensate can differ significantly in density and composition (Perry et al., 2003). Si also shows strong interactions with plant biomolecules such as cellulose (Perry and Lu, 1992), phenolor lignin-carbohydrate complexes (Inanaga and Okasaka, 1995; Inanaga et al., 1995), callose (Law and Exley, 2011), and proteins (Perry and Keeling-Tucker, 2003). Although little is known about these chemical interactions, $\mathrm{Si}$ possibly links to these complex plant biomolecules through dihydrogen bonds (Zhang et al., 2013). As different condensation locations are characterized by different plant biomolecules, this strong interaction with the organic plant environment may result in an additional chemical and spectral difference in silica between plant lineages, which may explain the better calibration model for graminoids separately. Plant lineages show a large variation in the absolute bSi concentration (Hodson et al., 2005), possibly 


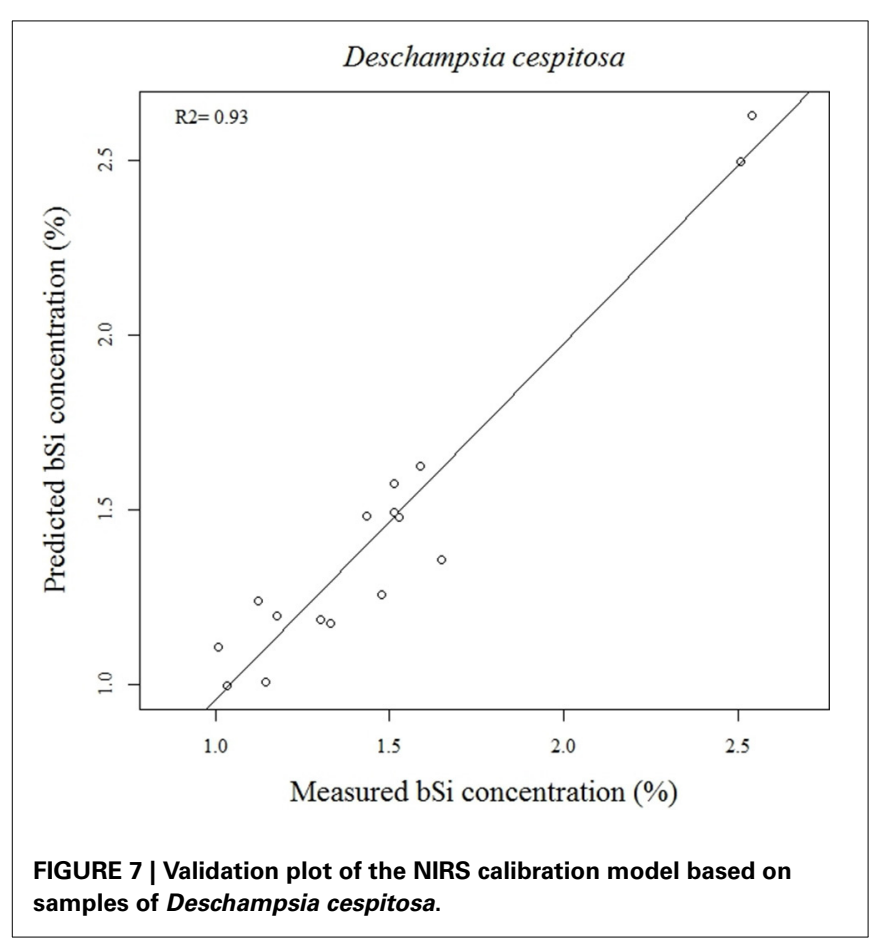

also influencing the characteristics of the individual Si condensates and its interactions with the organic environment. Finally, the three calibration models may also be confounded by other plant compounds as lignin, cellulose, and phenolics, which are, in some plant families, closely related to plant silica (Schoelynck et al., 2010; Cooke and Leishman, 2012). However, our dataset was not large enough to compare NIRS calibration model characteristics for different plant groups and further research is needed to assess the importance of plant group/species specific calibrations.

\section{METHOD EFFICIENCY AND COST, AND FUTURE CHALLENGES}

Using NIRS for plant $\mathrm{Si}$ analysis significantly reduces the operational and time costs. The time for sample drying is dependent on the amount of samples dried at the same time, but in all cases it is small and identical for both methods, and is therefore omitted from this estimation. In both methods, it took about 5 min to grind each sample using a ball-mill. In the reference method, about $30 \mathrm{mg}$ of each plant sample was weighed, bSi was extracted in an alkaline solution and the extract was analyzed spectrophotometrically. Because this reference method was already highly optimized, e.g., by using an automated spectrophotometric device (SKALAR, 332 samples per run), each of these three steps only took about $3 \mathrm{~min}$. When plant $\mathrm{Si}$ was analyzed by using NIRS scanning, it took $3 \mathrm{~min}$ per sample for the production of a tablet and $1.5 \mathrm{~min}$ per sample for the NIRS scan itself. As such, our calibration shows that the use of NIRS may reduce the analysis time by at least $30 \%$ compared to the chosen reference method for plant $\mathrm{Si}$ analysis, which is comparable to that reported for XRF spectroscopy (Reidinger et al., 2012). However, most time was still spent on the pre-treatment (drying, grinding, making tablet) of the plant sample. We believe that this pre-treatment may explain our strong calibration across largely differing plant species. However, omitting the grinding and rather extending the NIRS method to dried unground plant samples may be worthwhile as it results in a considerable progress in time efficiency, reducing the analysis time to $1.5 \mathrm{~min}$ after drying (90\% reduction). The application to unground samples would introduce the structure of the plant leaf as an important calibration factor. Leaf structure strongly differs between plant species. Although a scatter correction of the NIR spectra may reduce the influence of structure (e.g., Gislum et al., 2004), the earlier described plant family specific location of silica deposition probably requires separate calibrations for each plant family or even plant species. Application of NIRS on fresh plant material, which would exclude all sample pre-treatment and allow for in situ non-destructive field monitoring of plant silicon, shows some larger challenges as all wavelength zones with high influence on our calibration model were situated in zones typical for $\mathrm{O}-\mathrm{H}$ bonds of water, which should be avoided when working with fresh plant samples (e.g., Foley et al., 1998; Morón et al., 2007). Finally, we recommend other studies to carefully consider whether washing of the plant samples is needed in order to remove dust/soil particles. This will extend the analysis time, but is a common factor for both the chemical and the spectral analysis method.

An even stronger gain in efficiency and reduction in operational costs is obtained when applying NIRS for simultaneous analysis of different plant compounds. As a result of its central role in the functioning of plants, Si biochemistry in plants is closely linked to that of numerous other chemical compounds (Cooke and Leishman, 2011). Studies that quantify Si in plants often also quantify plant structural compounds such as lignin and cellulose (Schoelynck et al., 2010), as well as compounds related to abiotic and biotic plant stress (toxic metals, secondary metabolites) and plant macronutrients (e.g., $\mathrm{N}$ and $\mathrm{P}$ ). Numerous studies have shown the applicability of NIRS for the analysis of many of these Si-related plant compounds (e.g., Joffre et al., 1992; Gillon et al., 1999; Stolter et al., 2006; González-Martín et al., 2007). Especially in studies where focus is on different plant compounds, the advantages of using NIRS as a method are unprecedented both in efficiency and cost.

\section{CONCLUSIONS}

Our study shows that NIRS can be used to analyze silicon in plants, and as such represents a new promising method for measuring Si more effectively, at least $30 \%$ faster, and at minimal operational cost. We showed the applicability of a calibration model based on plant species across different plant families, and that accuracy can be gained by applying plant group or species-specific calibration models. Although XRF spectroscopy offers comparable advantages, we regard XRF and NIRS to be complementary with regards to the possibility of simultaneously analyzing elementary and organic compounds, respectively. As such, both methods provide scope for studies characterizing variation of bSi in natural ecosystems at much larger scales than previously possible with traditional chemical digestion methods and will open avenues for doing research on the role of $\mathrm{Si}$ in plants and ecosystems. 


\section{AUTHOR CONTRIBUTIONS}

Kari Anne Bråthen developed the research hypothesis and the study design. Adriaan Smis performed field sampling and chemical analysis, Francisco Javier Ancin Murguzur performed NIR scanning, calibration model development, and statistical analysis. The final manuscript is the end product of joint writing efforts of all authors.

\section{ACKNOWLEDGMENTS}

We thank Anne Cools and Tom Van der Spiet of the Ecosystem Management Research group at the University of Antwerp for helping with the chemical analyses. We thank Sissel Kaino from the Department of Arctic and Marine Biology (UiT-The Arctic University of Norway), for preparing all plant samples for NIRS scanning. Adriaan Smis received funding from FWO-Vlaanderen, the Research Foundation Flanders, for the PhD-fellowship "The effect of reindeer grazing on the biological Silicon buffer in subarctic ecosystems." We thank BELSPO (Belgian Science Policy) for funding the IAP project SOGLO ("The soil system under global change") and FWO for funding project "Silicate fertilization, crop production and carbon storage: a new and integrated concept for sustainable management of agricultural ecosystems" and funding project "an investigation of recently discovered controls on ecosystem soil nutrient stoichiometry in (sub)arctic ecosystems." Francisco Javier Ancin Murguzur and Kari Anne Bråthen received funding from the FRAM research program of "Effects of climate change on terrestrial ecosystems, landscapes, society and indigenous peoples," and Francisco Javier Ancin Murguzur, Soininen and Kari Anne Bråthen received funding from COAT (Climate-Ecological Observatory for Arctic Tundra). All authors confirm that they didn't receive payment or services from a third party for any aspect of the submitted work.

\section{REFERENCES}

Blecker, S. W., McCulley, R. L., Chadwick, O. A., and Kelly, E. F. (2006). Biologic cycling of silica across a grassland bioclimosequence. Glob. Biogeochem. Cycles 20, GB3023. doi: 10.1029/2006GB002690

Carey, J. C., and Fulweiler, R. W. (2013). Nitrogen enrichment increases net silica accumulation in a temperate salt marsh. Limnol. Oceanogr. 58, 99-111. doi: 10.4319/lo.2013.58.1.0099

Carnelli, A. L., Madella, M., and Theurillat, J.-P. (2001). Biogenic silica production in selected alpine plant species and plant communities. Ann. Bot. 87, 425-434. doi: 10.1006/anbo.2000.1355

Casler, M. D., and Shenk, J. S. (1985). Effect of sample grinding size on forage quality estimates of smooth bromegrass clones. Crop Sci. 25, 167-170. doi: 10.2135/cropsci1985.0011183X002500010040x

Chodak, M. (2008). Application of near infrared spectroscopy for analysis of soils, litter and plant materials. Pol. J. Environ. Stud. 17, 631-642.

Clark, D. H., Mayland, H. F., and Lamb, R. C. (1987). Mineral analysis of forages with near infrared reflectance spectroscopy. Agron. J. 79, 485-490. doi: 10.2134/agronj1987.00021962007900030016x

Cloern, J. E. (2001). Our evolving conceptual model of the coastal eutrophication problem. Mar. Ecol. Prog. Ser. 210, 223-253. doi: 10.3354/meps210223

Cooke, J., and Leishman, M. R. (2011). Is plant ecology more siliceous than we realise? Trends Plant Sci. 16, 61-68. doi: 10.1016/j.tplants.2010.10.003

Cooke, J., and Leishman, M. R. (2012). Tradeoffs between foliar silicon and carbonbased defences: evidence from vegetation communities of contrasting soil types. Oikos 121, 2052-2060. doi: 10.1111/j.1600-0706.2012.20057.x

Currie, H. A., and Perry, C. C. (2007). Silica in plants: biological, biochemical and chemical studies. Ann. Bot. 100, 1383-1389. doi: 10.1093/aob/mcm247
De Maesschalck, R., Jouan-Rimbaud, D., and Massart, D. L. (2000). The Mahalanobis distance. Chemometr. Intell. Lab. 50, 1-18. doi: 10.1016/S01697439(99)00047-7

DeMaster, D. J. (1991). Measuring biogenic silica in marine sediments and suspended matter. Geophys. Monogr. 63, 363-367.

Epstein, E. (1994). The anomaly of silicon in plant biology. Proc. Natl. Acad. Sci. U.S.A. 91, 11-17. doi: 10.1073/pnas.91.1.11

Epstein, E. (1999). Silicon. Annu. Rev. Plant Phys. 50, 641-664. doi: 10.1146/annurev.arplant.50.1.641

Foley, W. J., McIlwee, A., Lawler, I., Aragones, L., Woolnough, A. P., and Berding, N. (1998). Ecological applications of near infrared reflectance spectroscopy a tool for rapid, cost-effective prediction of the composition of plant and animal tissues and aspects of animal performance. Oecologia 116, 293-305. doi: $10.1007 / \mathrm{s} 004420050591$

Gillon, D., Houssard, C., and Joffre, R. (1999). Using near-infrared reflectance spectroscopy to predict carbon, nitrogen and phosphorus content in heterogeneous plant material. Oecologia 118, 173-182. doi: 10.1007/s004420050716

Gislum, R., Micklander, E., and Nielsen, J. P. (2004). Quantification of nitrogen concentration in perennial ryegrass and red fescue using near-infrared reflectance spectroscopy (NIRS) and chemometrics. Field Crop. Res. 88, 269-277. doi: 10.1016/j.fcr.2004.01.021

González-Martín, I., Hernández-Hierro, J. M., and González-Cabrera, J. M. (2007). Use of NIRS technology with a remote reflectance fiber-optic probe for predicting mineral composition ( $\mathrm{Ca}, \mathrm{K}, \mathrm{P}, \mathrm{Fe}, \mathrm{Mn}, \mathrm{Na}, \mathrm{Zn}$ ), protein and moisture in alfalfa. Anal. Bioanal. Chem. 387, 2199-2205. doi: 10.1007/s00216-006-1039-4

Halgerson, J. L., Sheaffer, C. C., Martin, N. P., Peterson, P. R., and Weston, S. J. (2004). Near-infrared reflectance spectroscopy prediction of leaf and mineral concentrations in Alfalfa. Agron. J. 96, 344-351. doi: 10.2134/agronj2004.0344

Herbauts, J., Dehalu, F. A., and Gruber, W. (1994). Quantitative determination of plant opal content in soils, using a combined method of heavy liquid separation and alkali dissolution. Eur. J. Soil Sci. 45, 379-385. doi: 10.1111/j.13652389.1994.tb00522.x

Hodson, M. J., White, P. J., Mead, A., and Broadley, M. R. (2005). Phylogenetic variation in the silicon composition of plants. Ann. Bot. 96, 1027-1046. doi: 10.1093/aob/mci255

Inanaga, S., and Okasaka, A. (1995). Calcium and silicon binding compounds in cell walls of rice shoots. Soil Sci. Plant Nutr. 41, 103-110. doi: 10.1080/00380768.1995.10419563

Inanaga, S., Okasaka, A., and Tanaka, S. (1995). Does silicon exist in association with organic compounds in rice plants? Soil Sci. Plant Nutr. 41, 111-117. doi: 10.1080/00380768.1995.10419564

Jin, S., and Chen, H. (2007). Near-infrared analysis of the chemical composition of rice straw. Ind. Crop. Prod. 26, 207-211. doi: 10.1016/j.indcrop.2007.03.004

Joffre, R., Gillon, D., Dardenne, P., Agneesens, R., and Biston, R. (1992). The use of near-infrared spectroscopy in litter decomposition studies. Ann. Sci. For. 49, 481-488. doi: 10.1051/forest:19920504

Kaufman, P. B., Bigelow, W. C., Schmid, R., and Ghosheh, N. S. (1971). Electron microprobe analysis of silica of epidermal cells in Equisetum. Am. J. Bot. 58, 309-316. doi: 10.2307/2441411

Kaye, W. (1954). Near infrared spectroscopy - I. Spectral identification and analytical application. Spectrochim. Acta 6, 257-287. doi: 10.1016/03711951(54)80011-7

Kelly, E. F., Chadwick, O. A., and Hilinski, T. E. (1998). The effect of plants on mineral weathering. Biogeochemistry 42, 21-53. doi: 10.1023/A:1005919306687

Kennard, R. W., and Stone, L. A. (1969). Computer aided design of experiments. Technometrics 11, 137-148. doi: 10.1080/00401706.1969.10490666

Law, C., and Exley, C. (2011). New insight into silica deposition in horsetail (Equisetum arvense). Plant Biol. 11:112. doi: 10.1186/1471-2229-11-112

Ma, J. F., Miyake, Y., and Takahashi, E. (2001). "Silicon as a beneficial element for crop plants," in Silicon in Agriculture. Studies in Plant Science,Vol. 8, eds L. E. Datnoff, G. H. Snyder, and G. H. Korndörfer (Amsterdam: Elsevier), 17-39.

Mahalanobis, P. C. (1936). On the generalised distance in statistics. Proc. Nat. Instit. Sci. India 12, 49-55.

Mark, H., and Workman, J. (1991). Statistics in Spectroscopy. New York, NY: Academic.

Martens, H., and Næs, T. (1993). Multivariate Calibration. New York, NY: Wiley.

Massey, F. P., Ennos, A. R., and Hartley, S. E. (2007). Grasses and the resource availability hypothesis: the importance of silica-based defences. J. Ecol. 95, 414-424. doi: 10.1111/j.1365-2745.2007.01223.x 
Meunier, J. D., Keller, C., Guntzer, F., Riotte, J., Braun, J. J., and Anuparna, K. (2013). Assessment of the $1 \% \mathrm{Na}_{2} \mathrm{CO}_{3}$ technique to quantify the phytolith pool. Geoderma 216, 30-35. doi: 10.1016/j.geoderma.2013.10.014

Mevik, B.-H., Wehrens, R., and Liland, K. H. (2013). Package 'pls': Partial Least Squares and Principal Component regression in R. Available online at: http://cran. r-project.org/web/packages/pls/pls.pdf

Møller, J. D., and Rasmussen, H. (1984). Stegmata in Orchidales: character state distribution and polarity. Bot. J. Linn. Soc. 89, 53-76. doi: 10.1111/j.10958339.1984.tb01000.x

Morón, A., Garcia, A., Sawchik, J., and Cozzolino, D. (2007). Preliminary study of the use of near-infrared reflectance spectroscopy to assess nitrogen content of undried wheat plants. J. Sci. Food Agric. 87, 147-152. doi: 10.1002/jsfa.2691

Moulton, K. L., West, J., and Berner, R. A. (2000). Solute flux and mineral mass balance approaches to the quantification of plant effects on silicate weathering. Am. J. Sci. 300, 539-570. doi: 10.2475/ajs.300.7.539

Ostatek-Boczynski, Z. A., Purcell, D. E., Keeff, E. C., Martens, W. N., and O'Shea, M. G. (2013). Rapid determination of carbon, nitrogen, silicon, phosphorus, and potassium in sugar mill by-products, mill mud, and ash using near infrared spectroscopy. Commun. Soil Sci. Plan. 44, 1156-1166. doi: 10.1080/00103624.2012.756004

Perry, C. C., Belton, D., and Shafran, K. (2003). Studies of biosilicas; structural aspects, chemical principles, model studies and the future. Prog. Mol. Subcell. Biol. 33, 269-299. doi: 10.1007/978-3-642-55486-5_11

Perry, C. C., and Keeling-Tucker, T. (2003). Model studies of colloidal silica precipitation using biosilica extracts from Equisetum telmatia. Colloid Polym. Sci. 281, 652-664. doi: 10.1007/s00396-002-0816-7

Perry, C. C., and Lu, Y. (1992). Preparation of silicas from silicon complexes: role of cellulose in polymerisation and aggregation control. J. Chem. Soc. Faraday Trans. 88, 2915-2921. doi: 10.1039/ft9928802915

Piperno, D. R. (1988). Phytolith Analysis: An Archaeological and Geological Perspective. San Diego: Academic.

Prychid, C. J., Rudall, P. J., and Gregory, M. (2004). Systematics and biology of silica bodies in monocotyledons. Bot. Rev. 69, 377-440. doi: 10.1663/00068101(2004)069[0377:SABOSB]2.0.CO;2

Ragueneau, O., Schultes, S., Bidle, K., Claquin, P., and Moriceau, B. (2006). Si and $\mathrm{C}$ interactions in the world ocean: importance of ecological processes and implications for the role of diatoms in the biological pump. Glob. Biogeochem. Cycles 20, GB4S02. doi: 10.1029/2006G. B.002688

Raven, J. A. (2003). Cycling silicon - the role of accumulation in plants. New Phytol. 158, 419-430. doi: 10.1046/j.1469-8137.2003.00778.x

R Development Core Team. (2013). R: A language and Environment for Statistical Computing. Vienna: R Foundation for Statistical Computing. Available online at: http://www.R-project.org

Reidinger, S., Ramsey, M. H., and Hartley, S. E. (2012). Rapid and accurate analyses of silicon and phosphorus in plants using a portable X-ray fluorescence spectrometer. New Phytol. 195, 699-706. doi: 10.1111/j.1469-8137.2012.04179.x

Saccone, L., Conley, D. J., and Sauer, D. (2007). Methodologies for amorphous silica analysis. J. Geochem. Exp. 88, 235-238. doi: 10.1016/j.gexplo.2005.08.045

Sangster, A. G., and Hodson, M. J. (1986). "Silica in higher plants," in Silicon Biochemistry, eds D. Evered and M. O’Connor (Chichester: John Wiley), 90-107.

Schaller, J., Brackhage, C., and Dudel, G. E. (2012). Silicon availability changes structural carbon ratio and phenol content of grasses. Environ. Exp. Bot. 77, 283-287. doi: 10.1016/j.envexpbot.2011.12.009

Schoelynck, J., Bal, K., Backx, H., Okruszko, T., Meire, P., and Struyf, E. (2010). Silica uptake in aquatic and wetland macrophytes: a strategic choice between silica, lignin and cellulose? New Phytol. 186, 385-391. doi: 10.1111/j.14698137.2009.03176.x

Shenk, J. S., and Westerhaus, M. O. (1994). "The application of near infrared spectroscopy (NIRS) to forage analysis," in National Conference on Forage Quality Evaluation and Utilization, eds G. C. Jr. Fahey, L. E. Mosser, D. R. Mertens, and M. Collins (Madison: American Society of Agronomy), 406-449.

Smith, J. D., and Milne, P. J. (1981). Spectrophotometric determination of silicate in natural waters by formation of $\alpha$-molybdosilicic acid and reduction with a tin(IV)-ascorbic acid-oxalic acid mixture. Anal. Chim. Acta 123, 263-270. doi: 10.1016/S0003-2670(01)83179-2

Stevens, A., and Ramirez-Lopez, L. (2014). An Introduction to the "Prospectr" Package in $R$. Available online at: http://cran.r-project.org/web/packages/ prospectr/prospectr.pdf

Stolter, C., Julkunen-Tiitto, R., and Ganzhorn, J. U. (2006). Application of near infared reflectance spectroscopy (NIRS) to assess some properties of a sub-arctic ecosystem. Basic Appl. Ecol. 7, 167-187. doi: 10.1016/j.baae.2005.05.002

Street-Perrott, A. F., and Barker, P. A. (2008). Biogenic silica: a neglected component of the coupled global continental biogeochemical cycles of carbon and silicon. Earth Surf. Proc. Land. 33, 1436-1457. doi: 10.1002/esp.1712

Struyf, E., and Conley, D. J. (2012). Emerging understanding of the ecosystem silica filter. Biogeochemistry 107, 9-18. doi: 10.1007/s10533-011-9590-2

Sundue, M. (2009). Silica bodies and their systematic implications in Pteridaceae (Pteridophyta). Bot. J. Linn. Soc. 161, 422-435. doi: 10.1111/j.10958339.2009.01012.x

Tréguer, P. J., and De La Rocha, C. L. (2013). The world ocean silica cycle. Annu. Rev. Mar. Sci. 5, 1-25. doi: 10.1146/annurev-marine-121211-172346

Vandevenne, F., Struyf, E., Clymans, W., and Meire, P. (2012). Agricultural silica harvest: Have humans created a new and important loop in the global silica cycle? Front. Ecol. Environ. 10, 243-248. doi: 10.1890/110046

Van Soest, P. J., and Jones, L. H. P. (1968). Effect of silica in forages upon digestibility. J. Diary Sci. 51, 1644-1648. doi: 10.3168/jds.S0022-0302(68) 87246-7

Zhang, C., Wang, L., Zhang, W., and Zhang, F. (2013). Do lignification and silicification of the cell wall precede silicon deposition in the silica cell of the rice (Oryza sativa L.) leaf epidermis? Plant Soil 372, 137-149. doi: 10.1007/s11104013-1723-z

Conflict of Interest Statement: The authors declare that the research was conducted in the absence of any commercial or financial relationships that could be construed as a potential conflict of interest.

Received: 29 April 2014; accepted: 07 September 2014; published online: 24 September 2014.

Citation: Smis A, Ancin Murguzur FJ, Struyf E, Soininen EM, Herranz Jusdado JG, Meire P and Bråthen KA (2014) Determination of plant silicon content with near infrared reflectance spectroscopy. Front. Plant Sci. 5:496. doi: 10.3389/fpls.2014.00496 This article was submitted to Functional Plant Ecology, a section of the journal Frontiers in Plant Science.

Copyright () 2014 Smis, Ancin Murguzur, Struyf, Soininen, Herranz Jusdado, Meire and Bråthen. This is an open-access article distributed under the terms of the Creative Commons Attribution License (CC BY). The use, distribution or reproduction in other forums is permitted, provided the original author $(s)$ or licensor are credited and that the original publication in this journal is cited, in accordance with accepted academic practice. No use, distribution or reproduction is permitted which does not comply with these terms. 